\title{
Using the Regional Ocean Modelling System (ROMS) to improve the sea surface temperature predictions of the MERCATOR Ocean System
}

\author{
PEDRO COSTA, BREOGÁN GÓMEZ, ANABELA VENÂNCIO, EVA PÉREZ \\ and VICENTE PÉREZ-MUNUUZURI \\ MeteoGalicia, Consellería de Medio Ambiente, Territorio e Infraestruturas, Xunta de Galicia, Rua Roma 6, \\ Santiago de Compostela, A Coruña, Spain. E-mail: pedro.melo@meteogalicia.es
}

\begin{abstract}
SUMMARY: Global models are generally capable of reproducing the observed trends in the globally averaged sea surface temperature (SST). However, the global models do not perform as well on regional scales. Here, we present an ocean forecast system based on the Regional Ocean Modelling System (ROMS), the boundary conditions come from the MERCATOR ocean system for the North Atlantic $\left(1 / 6^{\circ}\right.$ horizontal resolution). The system covers the region of the northwestern Iberian Peninsula with a horizontal resolution of $1 / 36^{\circ}$, forced with the Weather Research and Forecasting Model (WRF) and the Soil Water Assessment Tool (SWAT). The ocean model results from the regional ocean model are validated using real-time SST and observations from the MeteoGalicia, INTECMAR and Puertos Del Estado real-time observational networks. The validation results reveal that over a one-year period the mean absolute error of the SST is less than $1{ }^{\circ} \mathrm{C}$, and several sources of measured data reveal that the errors decrease near the coast. This improvement is related to the inclusion of local forcing not present in the boundary condition model.
\end{abstract}

Keywords: ROMS, WRF, MERCATOR, ocean modelling, Galician coast, sea surface temperature, freshwater.

\begin{abstract}
RESUMEN: Uso del modelo roms (Sistema de Modelado Oceánico Regional) para mejorar la predicción de LA TEMPERATURA DE LA SUPERFICIE DEL AGUA DE MAR DEL MODELo MERCATOR. - Los modelos globales son capaces de reproducir con suficiente fiabilidad las tendencias observadas a gran escala en la SST (temperatura la superficie del agua del mar, por sus siglas en inglés). Sin embargo estos modelos no muestran tanta precisión en escalas locales. En este trabajo se presenta un sistema de predicción oceánico basado en el modelo regional oceánico ROMS anidado al modelo oceánico MERCATOR (resolución $1 / 6^{\circ}$ ) para el Atlántico Norte. El sistema se extiende a lo largo del noroeste de la Península Ibérica con una resolución horizontal de $1 / 36^{\circ}$ y forzado con los modelos WRF para las condiciones atmosféricas y el modelo SWAT para los caudales de los ríos. El sistema de predicción se validó utilizando SST de OSTIA y observaciones provenientes de la redes de medición en tiempo real de Puertos del Estado, Intecmar y Meteogalicia. Los resultados muestran que para el periodo de un año estudiado el error medio absoluto de la SST es menor de $1{ }^{\circ} \mathrm{C}$, y las comparaciones contra observaciones puntuales muestran que este error es incluso menor cerca de costa. Los autores estiman que este comportamiento se debe a la inclusión de diferentes forzamientos locales no presentes en el modelo de condiciones de contorno.
\end{abstract}

Palabras clave: ROMS, WRF, MERCATOR, modelación oceánica, costa de Galicia, temperatura superficial del mar, agua dulce.

\section{INTRODUCTION}

The region of Galicia is located in the northwest of the Iberian Peninsula and is characterized by steep hills and sea inlets bathed by the Atlantic Ocean. The region's economy is strongly sea-dependent, particu- larly on the southwest coast characterized by coastal bays called rias. While most of the dynamics of the sea and weather is due to the presence of low- and highpressure systems in the mid-Atlantic Ocean (Carracedo et al. 2005), these finger-shape coastal structures have a strong influence on the local weather. Seasonal north- 
west winds, which occur mostly in the warm period of the year, pull surface waters towards the ocean and bring to the surface nutrient-rich deep sea water (Haynes et al. 1993, Peliz et al. 2002, Álvarez-Salgado et al. 2003). This upwelling phenomenon and freshwater discharges favour biological production processes along the coasts of Galicia, turning this area into one of the most productive ecosystems in the world. Here fisheries, aquaculture and sea-food harvesting are a major part of the economies of the region.

Coastal upwelling occurs when wind-driven Ekman transport (Ekman 1905) moves surface waters away from the coast; they are replaced by colder water that wells up from below the pycnocline and is rich in dissolved nutrients. This nutrient transport into the surface waters, where sunlight is present, results in rapid growth of phytoplankton populations. Since phytoplankton form the basis of marine food webs, the world's most productive fisheries are located in areas of coastal upwelling: about half the world's total fish catch comes from upwelling zones (Oliveira et al. 2009). The majority of the Galician population lives near the coast because of the economic importance of the natural resources, leisure activities and tourism in a region with over $1500 \mathrm{~km}$ of coast.

During the past 10 years, a number of agencies and research institutions around the world, and particularly in Europe, have developed strategies and methodologies for monitoring and predicting the evolution of the ocean and its coastal areas. Forecasting sea conditions for operational activities related to safety, pollution control, harmful algal blooms and effects of maninduced forcing on climate change are some of the issues addressed by most of these actions. As a result, high-resolution models have been implemented at the local-scale by a several agencies. However, predicting at local scales is difficult because of the limited predictability of the highly non-linear atmosphere-ocean system. Besides, the physics behind most of parameterizations within the ocean and atmosphere models is sometimes extended beyond the conditions for which the model is valid (Carracedo et al. 2005).

Several oil spill accidents that happened near the Galician coast have shown the environmental risks affecting this area. Forecasts providing continuous and reliable predictions of the future condition of the sea will improve the management of marine pollution accidents as well as other emergency situations at the sea (Balseiro et al. 2003). Offshore operations, navigation, coastal management and tourism are also critically dependent on the prevailing oceanographic conditions and can also benefit from high-resolution local ocean models. In this context, the implementation of an operational oceanographic system such as the one developed within the RAIA project is widely justified.

The objective of this project is to install a crossborder observational infrastructure and to develop an operational system based on the monitoring and prediction of the ocean environment. The consolidation of this infrastructure dedicated to the observation of the marine environment will place Galicia and northern Portugal among the leading regions of the world in the field of monitoring and modelling of the coastal zone. More information about this project can be found at the official web site for RAIA partners and users (http:// www.observatorioraia.org/).

In the framework of this project MeteoGalicia has developed an ocean forecasting system based on the Regional Ocean Modelling System (ROMS) (Shchepetkin and Mcwillians 2005). This forecasting system runs every day and covers the whole of the northwestern Iberian Peninsula at $0.02^{\circ}$ resolution for the next 96 h. Initial and boundary conditions are provided by the ocean global model developed at MERCATOR Océan (a French operator providing real-time and deferred ocean information services. More information can be found at the official web site at http://www.mercatorocean.fr/). In addition, local effects such as highresolution wind fields, fluxes between atmosphere and ocean and local river flows were included in the model. Although an extensive verification of this system has been made on different ocean parameters, here we will focus on showing how a limited-area, high-resolution model can improve the sea surface temperature (SST) forecasted by a global-scale, lower-resolution model that provides boundary conditions for the local model.

The phenomena cited at the beginning of this introduction directly or indirectly affect the SST. Upwelling and fresh water discharges produce a local impact on the SST near the coast and the same happens with the horizontal advection of surface warm and cold waters to the study region. Therefore, the SST can be interpreted as an indirect measurement of the model's skill at predicting these phenomena. For this reason we focus on this paper on the ability of ROMS to improve the SST of MERCATOR forecasted near the coast of the Galicia Region. Furthermore, we will show that a new proposed operational scheme consisting in restarting the model weekly with new initial conditions helps to resolve the errors in the SST forecasted by the MERCATOR numerical model. Section 2 presents the model's configuration, Section 3 describes the operational implementation and data sets used in the validation, Section 4 presents the validation results and discussion, and Section 5 presents the conclusions.

\section{MODELING SYSTEM AND METHODOLOGY}

\section{The ROMS model}

The present form of ROMS is an evolution of the S-Coordinate Rutgers University Model (SCRUM) described by Song and Haidvogel (1994). ROMS is a free-surface, hydrostatic, primitive equation ocean model that uses stretched, terrain-following coordinates in the vertical and orthogonal curvilinear coordinates in the horizontal. For the purpose of computational efficiency the code uses the natural time-scale separation 
of barotropic and baroclinic processes by employing a mode-splitting algorithm, which solves the vertically integrated barotropic momentum equations through a shorter step. A specially designed fast-time-averaging procedure prevents aliasing of processes unresolved by the longer baroclinic time step and maintains all necessary conservation properties (Shchepetkin and McWilliams 2005). The model has the option of several closure schemes for vertical turbulence, including MellorYamada (Mellor and Yamada 1982); surface fluxes are computed using standard bulk formulae (Fairall et al. 1996). A description of the ROMS model, associated post-processing software, and an extensive suite of model test problems are available online at the ROMS website: http://www.myroms.org/.

\section{The configuration of ROMS}

The model domain covers the northern Iberian Peninsula and extends approximately between $14^{\circ} \mathrm{W}$ and $4.5^{\circ} \mathrm{W}$ and between $38^{\circ} \mathrm{N}$ and $46^{\circ} \mathrm{N}$, as shown in Figure 1. The coordinate system is oriented as follows: $\mathrm{x}$ positive eastward, $\mathrm{y}$ northward and $\mathrm{z}$ upward. The bathymetry used has a size of $475 \times 400$ grid cells, with
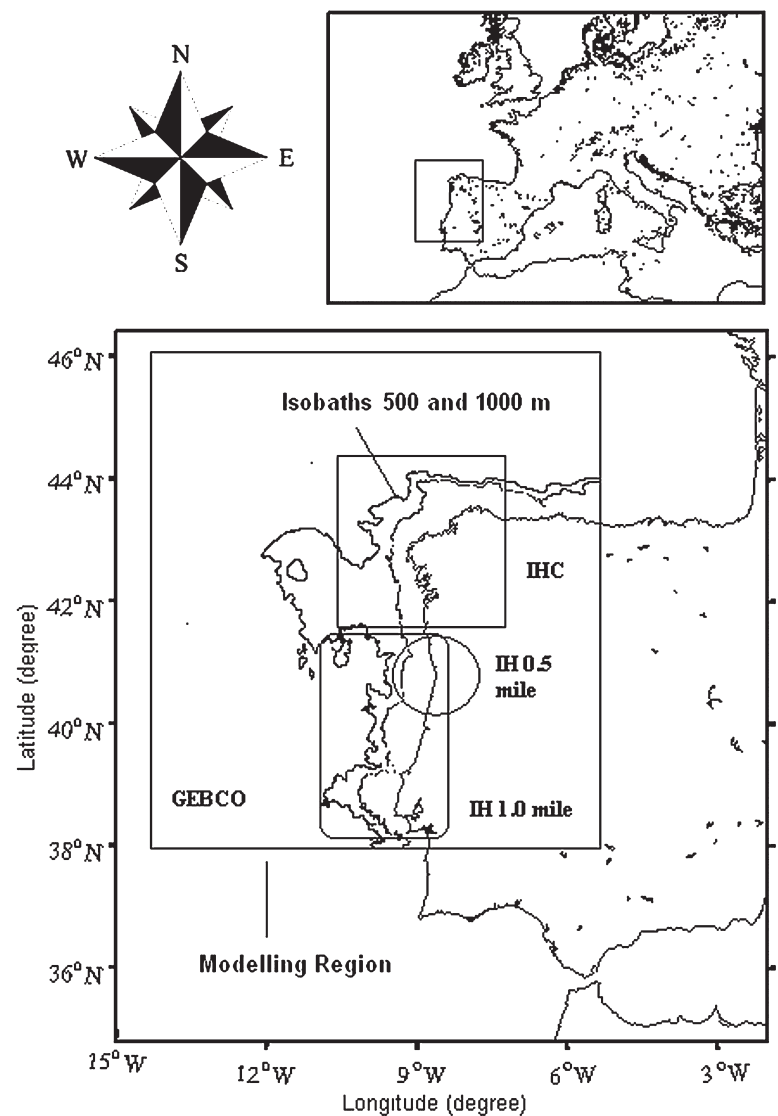

FIG. 1. - Study area (NW Iberian Peninsula) highlighting the modelling region and the four sources of the ocean topography: GEBCO topography (whole modelling region), IHC cartography (rectangle), $\mathrm{IH}$ cartography with 0.5 miles resolution (circle) and IH cartography with 1 mile resolution (rounded rectangle).
TABLE 1. - Basic model parameters.

\begin{tabular}{lcl}
\hline $\mathrm{L}$ & 474 & number of points in longitude direction \\
$\mathrm{M}$ & 399 & number of points in latitude direction \\
$\mathrm{N}$ & 41 & number of sigma levels \\
$\mathrm{h}_{\max }$ & $5000 \mathrm{~m}$ & maximum depth of the domain \\
$\mathrm{h}_{\min }$ & $25 \mathrm{~m}$ & minimum depth of the domain \\
$\theta_{\mathrm{s}}$ & 5 & sigma coordinate stretching factor \\
$\theta_{\mathrm{b}}$ & 0.4 & sigma coordinate bottom stretching factor \\
$\Delta_{\mathrm{t}}$ & $60 \mathrm{~s}$ & baroclinic time step \\
$\Delta_{\mathrm{tf}}$ & $20 \mathrm{~s}$ & barotropic time step \\
$\mathrm{v}$ & $5.0 \mathrm{~m}^{2} \mathrm{~s}^{-1}$ & Laplacian horizontal viscosity \\
$v_{\mathrm{t}}$ & $5.0 \mathrm{~m}^{2} \mathrm{~s}^{-1}$ & Laplacian horizontal diffusivity \\
$\mathrm{r}$ & $3.010^{-4} \mathrm{~m} \mathrm{~s}^{-1}$ & linear bottom drag coefficient \\
\hline
\end{tabular}

a horizontal spatial resolution of $0.02^{\circ}$ and minimum depth of $25 \mathrm{~m}$. The vertical discretization consists of 41 levels following the topography, with $h_{c}=50 \mathrm{~m}$ and a surface stretching factor of $\theta_{s}=5$ maintaining high resolution throughout the surface layers (i.e. boundary layers) of the domain. $\theta$ is a refinement parameter that determines the magnitude of stretching of the vertical grid in either the surface $\left(\theta_{\mathrm{s}}\right)$ or bottom layers $\left(\theta_{\mathrm{b}}\right) . h_{c}$ is a depth above which the vertical grid spacing of the sigma layers becomes (a) nearly uniform and (b) nearly independent of local depth, $h$, as long as $h>>h_{c}$. The turbulence closure is GLS (Generic Length Scale: Umlauf and Burchard 2003) with Canuto A stability functions (Canuto et al. 2001). Other parameters such as those associated with vertical resolution are described briefly in Table 1 .

The task of the open boundary condition (OBC) is to supply the external information needed by the limited-area model domain at the boundaries, while at the same time allowing information generated within the model domain to exit through the boundaries with minimal artificial influence on the internal solution (Mason et al. 2011). ROMS has different ways to specify the boundary conditions, including the Clamped, Flather, Champman and Radiation schemes. In this initial approach to the operational implementation it was not possible to test all the options so it was decided to use to simplest scheme, which was the Clamped type. Here the external data are provided along single rows at the open boundaries, i.e. there is no nudging over the interior boundary layer, although the performance of the $\mathrm{OBC}$ and the quality of the external data are critical (Mason et al. 2011). Horizontal viscosity coefficient and diffusion are allowed to be constant over the entire computational domain, with values of $37 \mathrm{~m}^{2} \mathrm{~s}^{-1}$ and $71 \mathrm{~m}^{2} \mathrm{~s}^{-1}$, respectively. Clamped-type boundary conditions are prone to introduce more noise than other schemes. Some basic tests were made to check whether the amount of noise of the Clamped boundary condition scheme was significantly higher than that of the other schemes. We concluded that the compromise made was acceptable but that more comprehensive tests should be performed.

For the barotropic mode, the normal velocity component uses a Flather-type condition (Flather 1976) based on radiation and the prescription of characteristic variables (Riemann invariants: Blayo and Debreu 
2005). A Chapman boundary condition is applied to the free surface, making the assumption that the dominant physical processes are surface gravity waves, in order to allow incoming surface gravity waves specified by the external data to enter the computational domain, while at the same time achieving unimpeded radiation for the outgoing waves (Chapman 1985). The baroclinic mode uses a Dirichlet (Clamped-type) condition for the normal velocity components of the momentum equations. The goal of this widely used class of $\mathrm{OBC}$ is to relax the model solution towards (or in the vicinity of) the external data. Tracers use a Clamped scheme similar to that for the normal velocity above.

In order to ensure a more realistic bathymetry near the coast, the final topography of the model was obtained from the general bathymetric chart of the oceans (GEBCO) with 30 arc-second resolution, and cartography from two governmental institutions: the Instituto Hidrográfico de la Marina, Cádiz (IHC) and the Instituto Hidrográfico Português (IH). To prevent aliasing when interpolating to the model grid, the raw topographies are smoothed using a Gaussian filter with a width twice the size of each raw data point. The interpolated topographies are then further smoothed by iteratively applying a filter to reduce the r-factor to below 0.2 (Haidvogel and Beckmann 1999). The two cartography sources were acquired within the RAIA project (Fig. 1)

Tides are included in the ROMS simulation with eight tidal constituents (M2, S2, N2, K2, K1, O1, P1, and Q1) from the OSU TOPEX/Poseidon Global Inverse Solution version 7.2 (Egbert et al. 1994). The tidal constituents were provided as complex amplitudes of earth-relative sea-surface elevation at a $1 / 4$ degree of resolution on a full global grid and were then interpolated to the ROMS model boundaries.

\section{Meteorological forcing}

Sea-level pressure, surface winds, surface air temperature, surface specific humidity, downward long wave radiation at the surface, downward short wave radiation at the surface and precipitation hourly values were extracted from the 12-km horizontal-resolution operational meteorological forecast system (covering the whole of the Iberian Peninsula) implemented in MeteoGalicia and are used to provide atmospheric forcing for ROMS through the use of the bulk flux algorithm (Fairall et al. 2004). MeteoGalicia runs the WRF model twice a day (00 and 12 UTC) on three different-resolution domains (36, 12 and $4 \mathrm{~km})$ using as a boundary condition the solution of the Global Forecast System (GFS) model. The WRF model (advanced research version) is a fully compressible non-hydrostatic model and uses higher-order numerics; this includes the Runge-Kutta $2^{\text {nd }}$ and $3^{\text {rd }}$ order time integration schemes, and $2^{\text {nd }}$ to $6^{\text {th }}$ order advection schemes in both horizontal and vertical directions. A time-split small step for acoustic and gravity wave modes is used (WRF
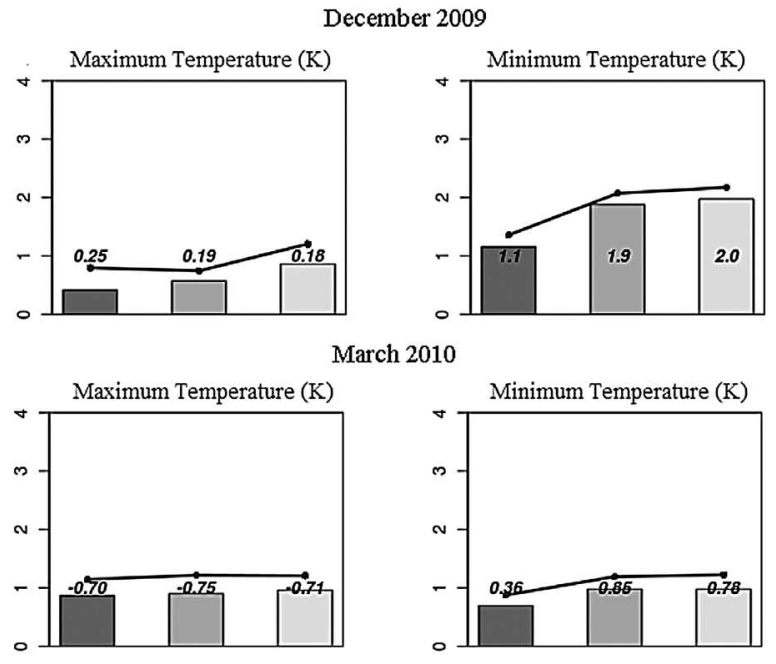

August 2010

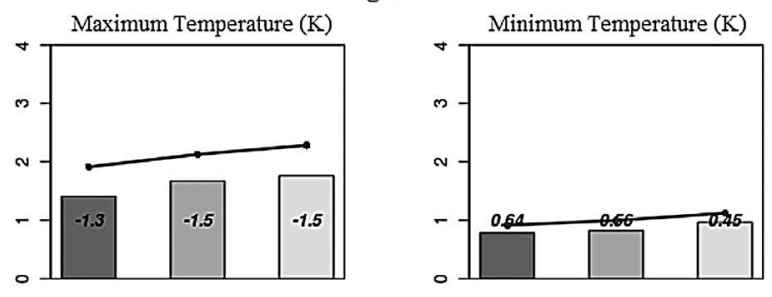

October 2010
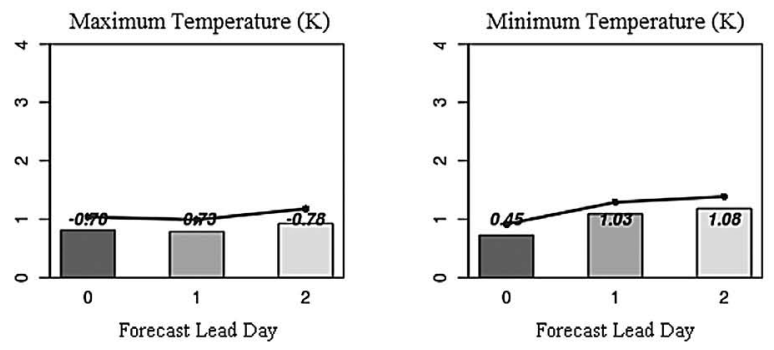

FIG. 2. - WRF model $2 \mathrm{~m}$ maximum and minimum temperature verification at Ons Island surface observation for three different lead days: D0, D1 and D2 ( $24 \mathrm{~h}, 48 \mathrm{~h}$ and $72 \mathrm{~h}$ forecasts). The BIAS is shown in numbers, the MAE in columns and the RMSE in solid line. Four different monthly periods are shown from December 2009 to December 2010.

modelling system user's guide 2007). Additional information about the implementation of this operational meteorological forecast system and the quality of the forecast provided by MeteoGalicia can be found on the official web page (http://www.meteogalicia.es/). The WRF model started to run operationally in summer 2008 and monthly statistics are performed on a routine basis. At the time of this manuscript more than two and a half years of simulations have been performed and compared against surface observations, showing a good performance, especially for predicting wind flow over the ocean. It is difficult to validate atmospheric variables over the ocean because few observations are available. To estimate WRF model performance over the ocean we compared the temperature measured at the Cies buoy (see location in Fig. 8) against the model forecasted at the closest grid point (Fig. 2). Buoys gen- 

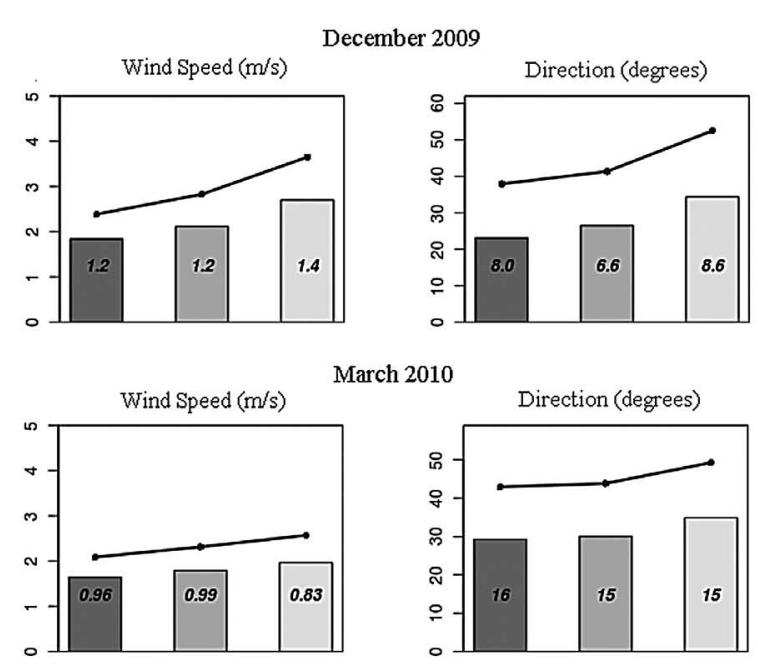

August 2010
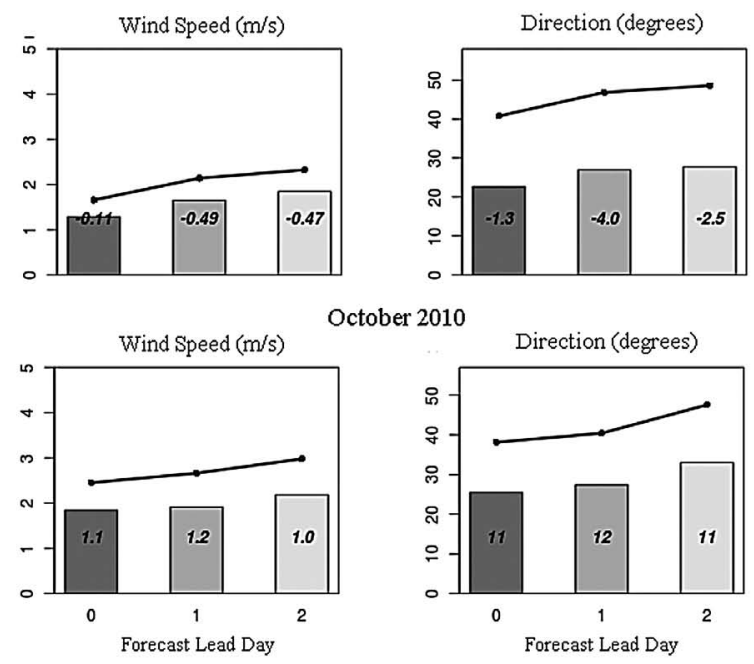

FIG. 3. - WRF model $10 \mathrm{~m}$ wind speed and direction verification at the Cies buoy for 3 different lead days: D0, D1 and D2 (24 h, 48 $\mathrm{h}$ and $72 \mathrm{~h}$ forecasts). The BIAS is shown in numbers, the MAE in columns and the RMSE in solid line. Four different monthly periods are shown from December 2009 to December 2010.

erally do not measure wind, and the Cies buoy is no exception, so we compared the wind at the Ons Island (see location in Fig. 4) surface observation, which is very close to the Cies buoy (Fig. 3). Four monthly periods we selected to show the performance at different times of the year: December 2009, and March, August and October 2010. In all the periods the model showed good skill at predicting these variables.

\section{River forcing}

The rivers in the Galicia region play an important role in coastal processes (Álvarez-Salgado et al. 1996), so it was decided to introduce their effects in the model to obtain acceptable ocean environment simulations near the coast. River run-off can be seasonally important in most rias (above all in the Rías Baixas, whereas

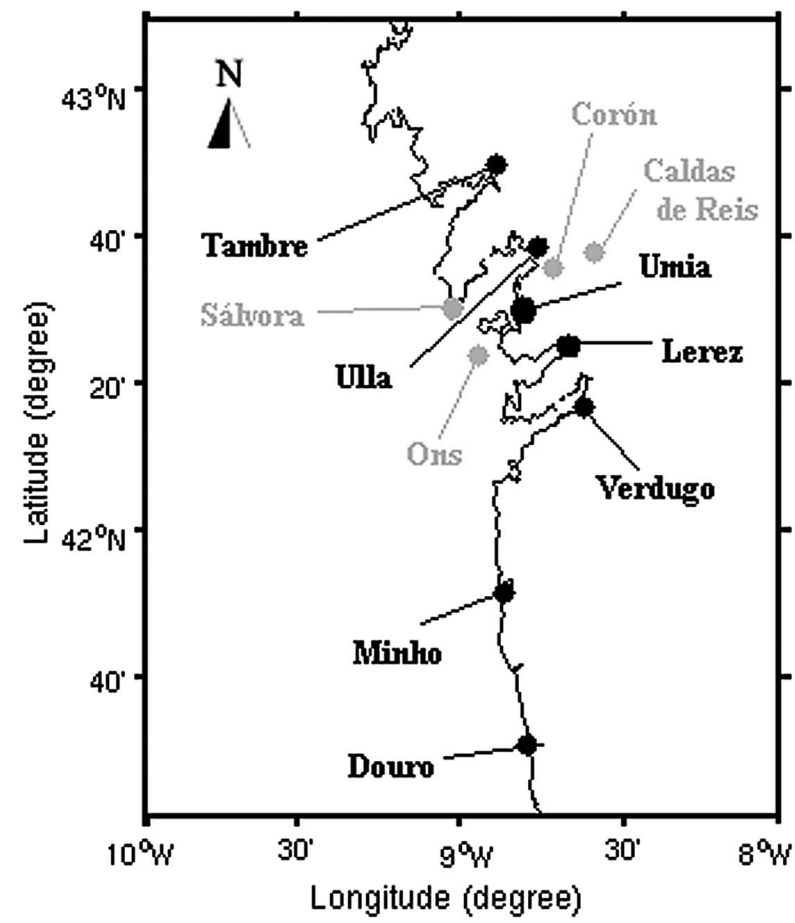

FIG. 4. - Map with the locations of the rivers and meteorological stations. The gray spots correspond to the meteorological stations.

the Rías Altas receive smaller inputs of freshwater), contributing significantly to the water dynamics and biogeochemistry (Álvarez-Salgado et al. 1996, Bode et al. 1998). The major flow contribution for this system comes from the Douro, Minho, Verdugo, Lerez, Umia, Ulla and Tambre rivers (Fig. 4). The mean run-off of those particular rivers can be seen in Table 2.

Flow measurements at the mouth of the rivers are very difficult to acquire, so the alternative is to use a hydrological model to simulate their flows. The modelling system implemented is the Soil Water Assessment Tool (SWAT), a watershed scale model developed by Agricultural Research Service and Texas A\&M University.

The model was developed to predict the impact of land management practices, such as vegetative changes, reservoir management, groundwater withdrawals, water transfer, sediment and agricultural chemical yields in large complex watersheds with varying soils, land use, and management conditions over long periods of time (Arnold et al. 1998, Neitsch et al. 2000). The SWAT model operates on daily time steps and the basic inputs to feed the model are the digital elevation model, soil classification, land use and meteorological

TABLE 2. - River mean run-off $\left(\mathrm{m}^{3} / \mathrm{s}\right)$

\begin{tabular}{lc}
\hline Douro & 650 \\
Minho & 479 \\
Verdugo & 23 \\
Lerez & 20 \\
Umia & 26 \\
Ulla & 52 \\
Tambre & 65
\end{tabular}



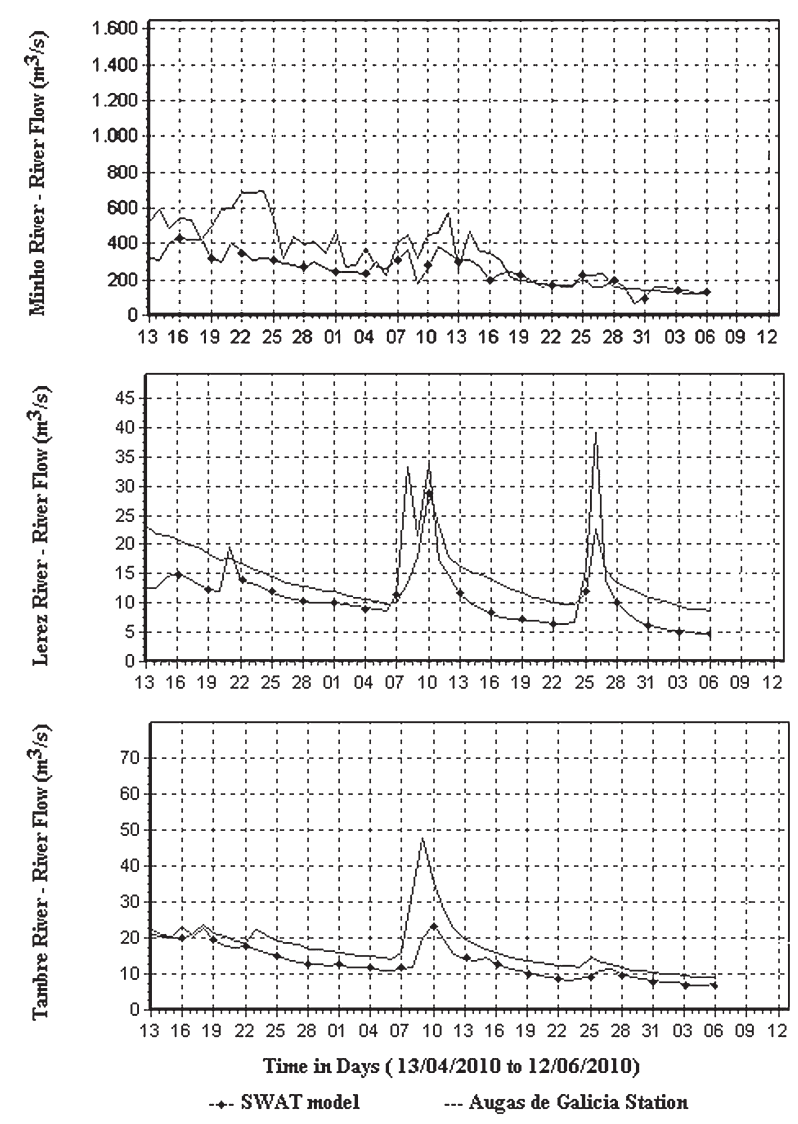

FIG. 5. - Example of the validation for the river flow forecasted by the SWAT model. The Lerez, Tambre, Umia and Minho rivers from 23 April 2011 to 23 June 2011.

data. The river basin is divided into smaller areas according to their characteristics, and the hydrological cycle is calculated by the water balance equation for each sub-basin; details can be found in the literature (Srinivasan et al. 1995).

The SWAT model runs on an operational daily basis and provides average daily flow for the Minho, Verdugo, Lerez, Umia, Ulla and Tambre rivers. A two-month discharge period of validation against the Augas de Galicia stations is shown in Figure 5. Here it is possible to see the limitation of the SWAT model for accurately predicting the river run-off but also its ability to reproduce its variance, following wet and dry periods with reasonable skill. While in some periods the magnitude of the predicted river flow has a significant error, we understand that this compromise is better than introducing a constant climatological value that will miss the variability of the river dynamics. Because of the lack of input data for the Douro river, it is not possible to simulate its flow and a climatic monthly average is used instead.

\section{Downscaling methodology}

The MERCATOR Océan system is based on highresolution ocean general circulation models (OGCM), real-time processing of remotely-sensed and in situ observations and data assimilation techniques. Three prototypes of the MERCATOR system are currently running: a global coarse-resolution $\left(2^{\circ}\right)$ configuration, a medium-resolution one $\left(1 / 3^{\circ}\right)$ in the north and equatorial Atlantic, and a high-resolution one $\left(1 / 6^{\circ}\right)$ in the North Atlantic and Mediterranean. (S. Baudel and V. Toumazou, pers. comm.). ROMS has been nested with the MERCATOR North Atlantic model because information is available on a near-real-time and routine basis, providing weekly near-real-time analysis and two-week forecasts; and with data assimilation on reanalysis mode.

The downscaling of the MERCATOR model was one of the most problematic issues when this operational setup was developed because of the great differences in the bathymetry near the coast (Fig. 6) and in the vertical discretization. ROMS uses stretched terrain following coordinates, while MERCATOR output is provided in geopotential coordinates.

To achieve satisfactory initial and boundaries conditions for ROMS, four steps were performed: First, there are ocean points masked within the solution provided by MERCATOR that must be filled in order to produce a complete representation of the ocean condition. Therefore a nearest neighbour interpolation in which every point is connected with every neighbour (horizontally, vertically and diagonally) is applied. Second, interpolation of the MERCATOR model output to the Northern Galicia ROMS grid is achieved by
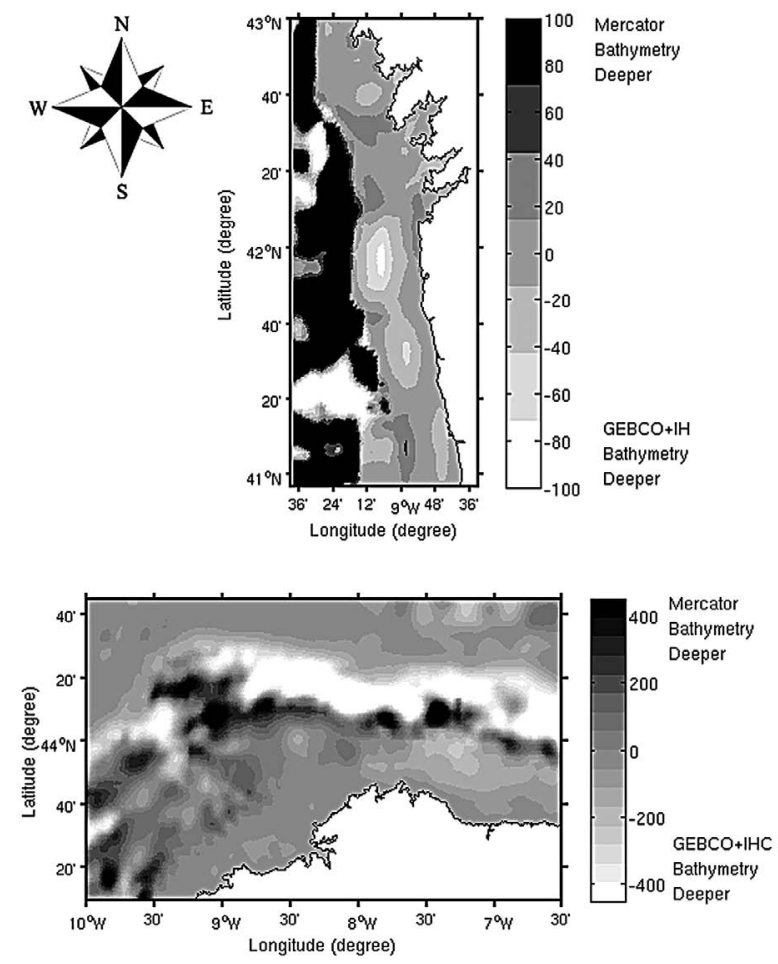

FIG. 6. - Differences (m) between MERCATOR bathymetry and ROMS (GEBCO + IHC + IH topographies) model final bathymetry. 
applying three-dimensional field optimal interpolation. This method allows arbitrarily located observations (MERCATOR solution) to be interpolated to a regular grid using a background field as a first guess. Optimal interpolation merges observations and background taking their expected variances into account. The merged field is optimal with respect to the expected variances of the interpolated fields. This interpolation method was chosen over other methods because a code apparatus was already built to create the model bathymetry. Other, less complicated methods such as bilinear interpolation would probably work as fine and probably much faster. Third, when the velocity fields are interpolated from one grid to another, it is almost inevitable that some interpolation noise will be induced on the integrated two-dimensional velocity field, so it is essential to perform a consistency test between the sea surface height field and the two-dimensional and three-dimensional velocities (M. Curie pers. comm.). Velocity consistency was ensured using the following expressions:

$\mathrm{u}(\mathrm{ROMS})=\mathrm{u}($ interpolated from MERCATOR to ROMS) - ubar (ROMS) + ubar (MERCATOR)

$\mathrm{v}(\mathrm{ROMS})=\mathrm{v}($ interpolated from MERCATOR to ROMS $)-\operatorname{vbar}($ ROMS $)+\operatorname{vbar}($ MERCATOR)

where $\mathrm{u}$ is the $\mathrm{x}$ momentum component, ubar is the vertically integrated $\mathrm{x}$ momentum component, $\mathrm{v}$ is $\mathrm{y}$ momentum component, and vbar is the vertically integrated y momentum component. Fourth, a secondorder Shapiro filter (Shapiro 1970, Durran 1998) was applied to accommodate the temperature and salinity gradient.

\section{Operational implementation}

Within the RAIA project (Iberian Margin Ocean Observatory), real-time monitoring and basin-shelf marine forecasting system have been implemented (Fig. 7), and since December 2010 the system is being used in operational mode for the northwestern Atlantic Ocean. The numerical forecasting model used is based on ROMS.

Every week the MERCATOR operational system produces 7 days of analysis and 14 days of forecast. To accommodate our operational system to these weekly period, two systems were developed with ROMS: a hindcast system that runs on a weekly basis and a forecast system that runs on a daily basis. The hindcast system ( 7 days) is forced at the surface by the WRF atmospheric analysis from the past 7 days and uses the MERCATOR analysis as initial and lateral boundary conditions. The ROMS forecast system, which runs for $96 \mathrm{~h}$ of simulation, is initialized using the last available ROMS forecast. This forecast comes from the hindcast system at the beginning of the 7 day period or the 24hour forecast system. This system is forced using WRF

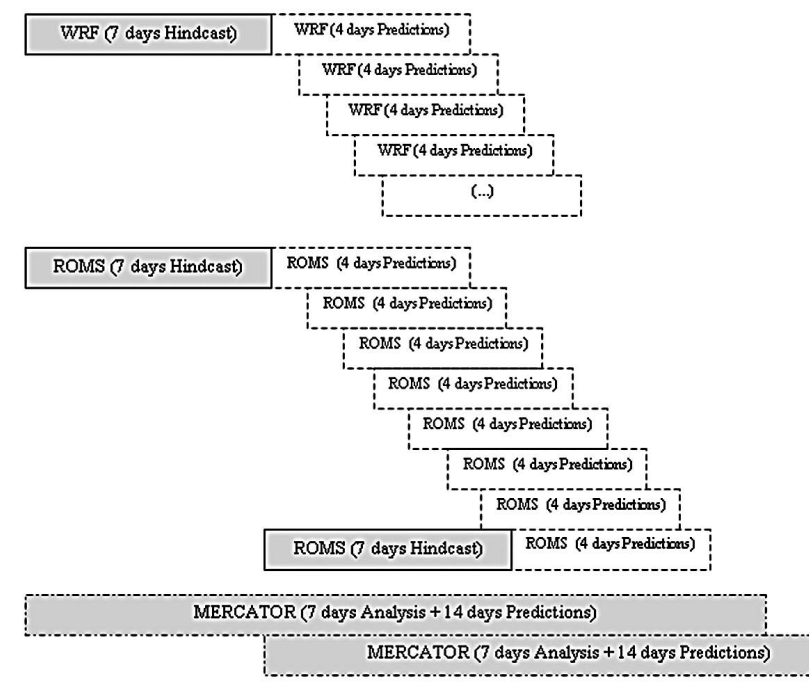

FIG. 7. - Schematic of the ocean operational forecast run by MeteoGalicia for the northwestern Iberian Peninsula.

and MERCATOR forecast fields. The operational model runs every day and the results are freely available in a dedicated Thredds server for research and commercial use.

This restart strategy was used to ensure that the ROMS solution stays close to the real evolution of the ocean. Our ROMS system does not perform any kind of data assimilation, unlike MERCATOR, which means that the only information from measured data is indirectly fed through the boundaries. This restart strategy aims to prevent the model from drifting to its own climate and keeps the solution close to the observed state of the ocean.

\section{OBSERVATIONAL DATA}

The results from ROMS were compared with two different sources of observations: OSTIA satellite data and temperature measured at moored stations. Although there are several in situ observations from moored buoys in the area of interest, a truly global coverage is only obtainable from satellite-borne instruments. It should be taken into consideration that satellites only take measurements on a thin layer of the ocean surface, whereas models represent SST in a layer of variable thickness of several centimetres depth. We considered these effects negligible for this study. OSTIA satellite data have been developed at the United Kingdom National Weather Service (Met Office) and the output is a daily, global coverage $1 / 20^{\circ}$ combined SST. For the comparison between the satellite and the model SST, the hourly model temperatures of the upper level of the model were linearly interpolated to the same spatial and temporal grid of the satellite images.

In the framework of the EROCIPS, EASY and RAIA projects financed through the European Union Interreg programme, a network of real-time ocean-meteorological stations along the Galician coast were deployed by 


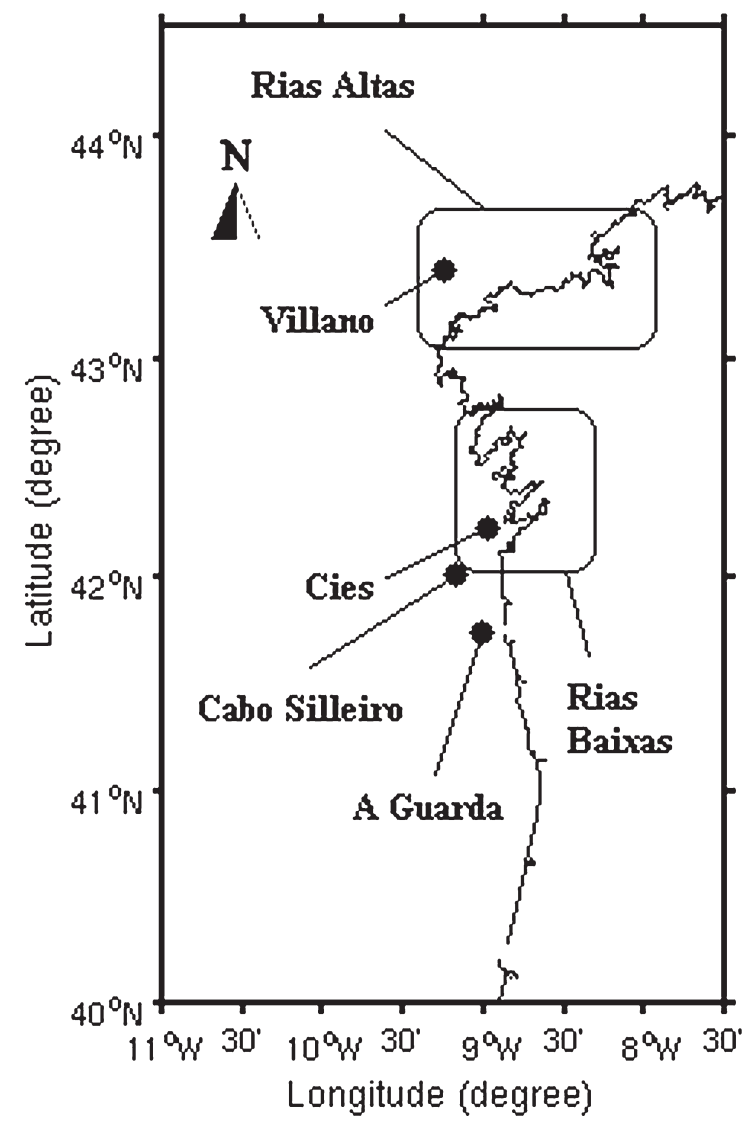

FIG. 8. - Map with the locations of the ocean-meteorological stations.

MeteoGalicia and INTECMAR, in collaboration with the Group of Physical Oceanography of the University of Vigo. A Guarda (Fig. 8; $41.9^{\circ} \mathrm{N}, 8.9^{\circ} \mathrm{W}$ ) and the Cies platform (Fig. $8 ; 42.17^{\circ} \mathrm{N}, 8.91^{\circ} \mathrm{W}$ ) belong to this network and are equipped with a SBE 37-IMP MicroCAT high-accuracy conductivity and temperature sensor at $0.5 \mathrm{~m}$ depth. In addition, the Seawatch (Oceanor) buoys off Cabo Silleiro (Fig. $8 ; 42.12^{\circ} \mathrm{N}, 9.43^{\circ} \mathrm{W}$ ) and Villano-Sisargas (Fig. 8; $43.5^{\circ} \mathrm{N}, 9.21^{\circ} \mathrm{W}$ ) belonging to the Puertos del Estado buoy network were also used to perform the sea temperature validation.

\section{RESULTS AND DISCUSSION}

To give statistical representativeness to this study, a year of simulations from December 2009 to December 2010 were run. Emphasis was placed on two particular periods corresponding to a rainy month in winter (December 2009) and an upwelling month in summer (August 2010). The SST forecasted by ROMS and MERCATOR were compared against OSTIA satellite data and buoy time series. The average magnitude of the difference between the forecast and observations (BIAS), the mean absolute error (MAE, the average of the absolute value of the difference between the model and observations) and the root mean square error (RMSE, the quadratic scoring rule which measures the root average quadratic distance between the model and observations) were used as skill scores to study the performance of the model. The three scores complement each other and give different statistical information about the errors. The BIAS typically measures the difference between model predictions and observations, the MAE measures the average magnitude of the errors, and the RMSE measures the spread of the distribution of the differences between the model and observations, thus giving information about how wide is its.

The annual mean SST comparison in Figure 9 shows that throughout the whole of the computational domain the bias parameter of the sea surface temperature from ROMS is between $-1^{\circ} \mathrm{C}$ and $1^{\circ} \mathrm{C}$. The largest observed differences occur between $14^{\circ} \mathrm{W}$ and $11^{\circ} \mathrm{W}$; for this particular region there is a positive BIAS according with higher MAE values (Fig. 9, right image). During the whole period analysed, results show a slight tendency of ROMS to underestimate the SST near the coast; the highest MAE values are located near the coast (greater than $1^{\circ} \mathrm{C}$ ). Similar results were obtained for the annual mean SST forecasted by MERCATOR, with the exception that in the region between $14^{\circ} \mathrm{W}$ and $11^{\circ} \mathrm{W}$ it is not possible to observe higher BIAS and MAE values. For this annual period it can be seen that ROMS has a better performance in the BIAS while MERCATOR has a slightly better performance in the MAE.
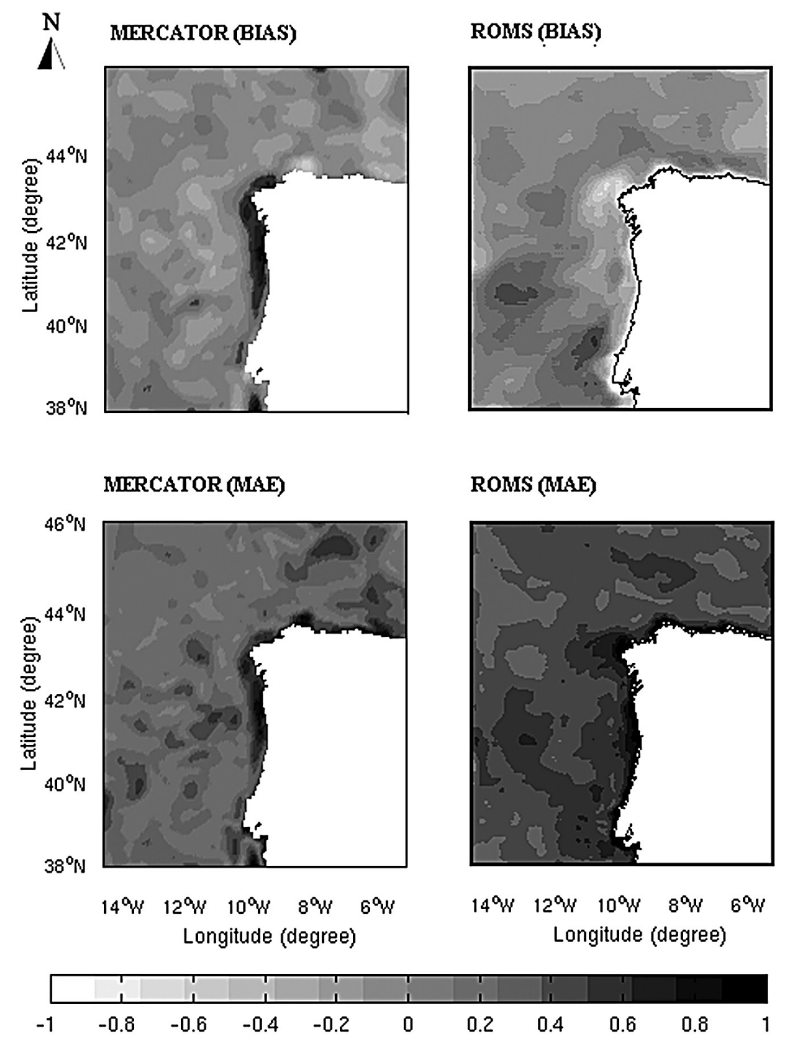

FIG. 9. - Distribution of the statistical parameter BIAS (left) and MAE (right) for the sea surface temperature forecasted by MERCATOR (above) and ROMS (below) from December 2009 to December 2010 compared against OSTIA SST. 
Winter 2009 was wet and December 2009 was particularly rainy (Fig. 10). Figure 11 shows the monthly average of the BIAS and RMSE for ROMS (right) and MERCATOR (left). For both models the SST were compared against OSTIA satellite data. The results show that MERCATOR has the highest BIAS and RMSE near the western and northern coast of the northwestern Iberian Peninsula, whereas this feature disappears in ROMS. However, the SST overestimation area forecasted by ROMS between the $14^{\circ} \mathrm{W}$ and $11^{\circ} \mathrm{W}$ is present again.

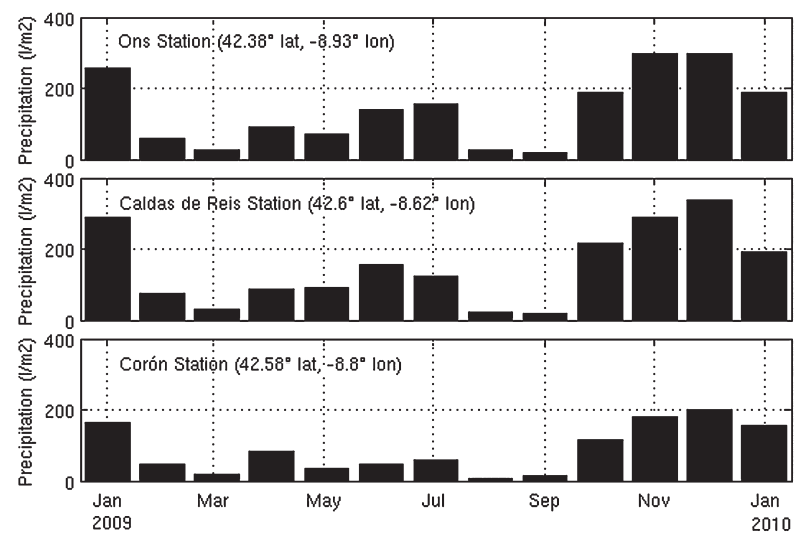

FIG. 10. - Time series of the precipitation accumulated at the Ons, Caldas de Reis and Corón meteorological stations for a one-year period.

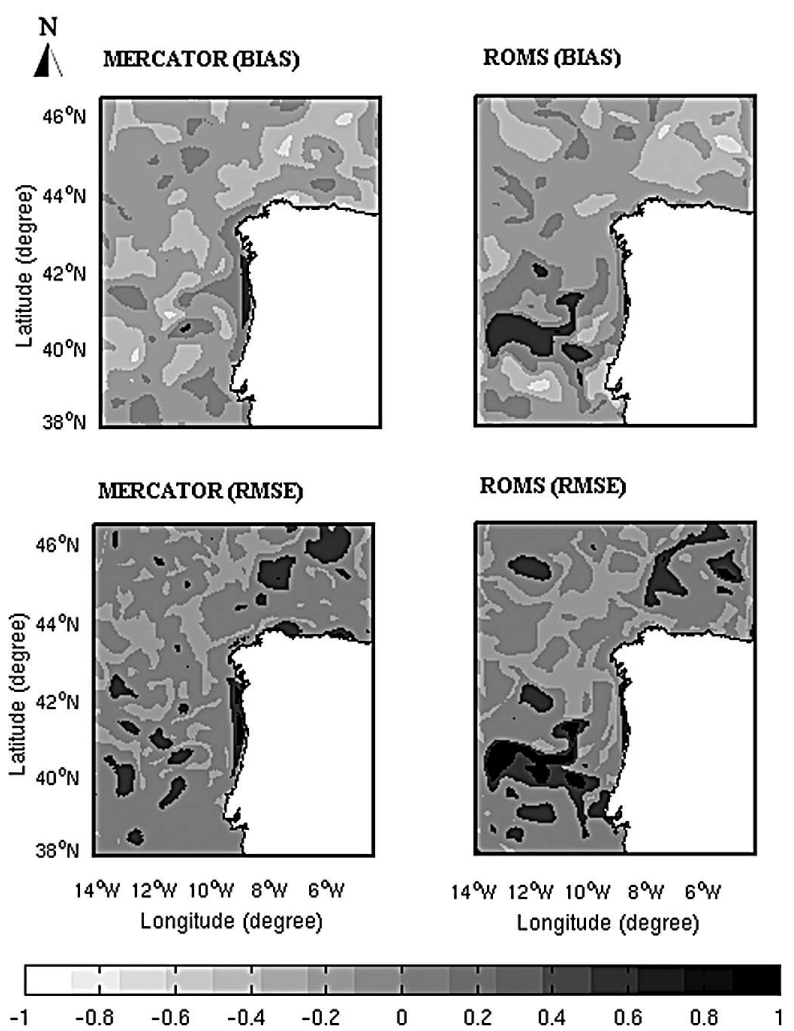

FIG. 11. - Horizontal distribution of the statistical parameter RMSE and BIAS for sea surface temperature in December 2009: (left) MERCATOR model and (right) ROMS model.

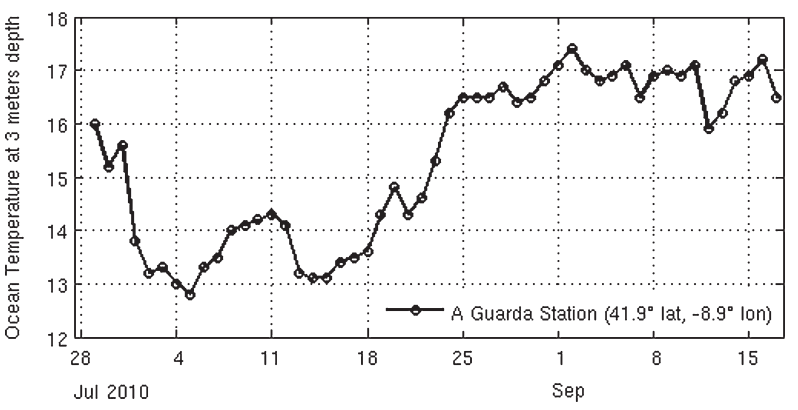

FIG. 12. - Time series of the ocean temperature at $3 \mathrm{~m}$ depth, from 28 July to 15 August 2010, at the A Guarda buoy location.
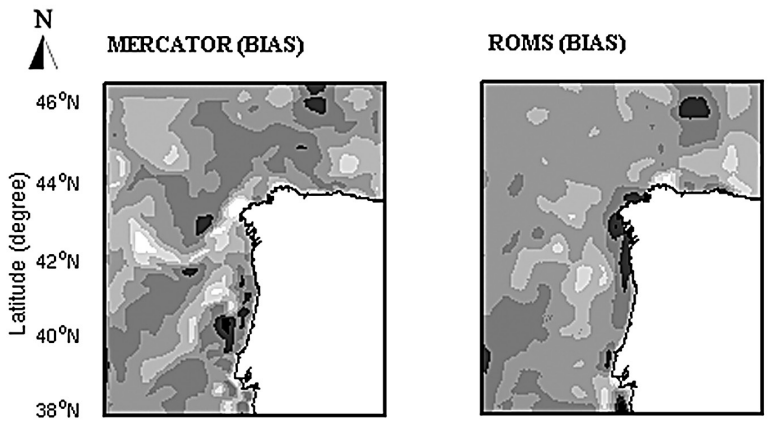

MERCATOR (RMSE)

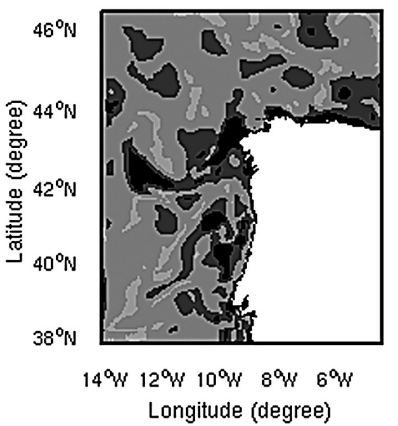

ROMS (RMSE)

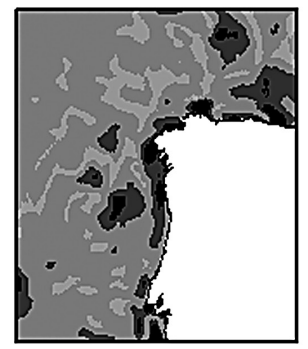

$14^{\circ} \mathrm{W} 12^{\mathrm{q}} 10^{\circ} \mathrm{W} 8 \mathrm{~W} 6 \mathrm{~W}$ Longitude (degree)

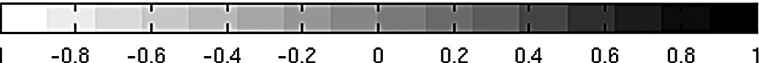

FIG. 13. - Horizontal distribution of the statistical parameter RMSE and BIAS for sea surface temperature in August 2010: (left) MERCATOR model and (right) ROMS model.

A strong episode of upwelling occurred on the Western Iberian Shelf in August 2010 (Fig. 12 between 4 and 18 August). The BIAS and RMSE for ROMS (right) and MERCATOR (left) show mixed result for this period. The BIAS shows a better performance for ROMS than for MERCATOR while in the RMSE the improvement is not so clear. At $42^{\circ} \mathrm{N}$, near the coast, ROMS shows a better performance, as was seen in the rainy period, but further north, around $43^{\circ} \mathrm{N}$, ROMS shows a higher RMSE than MERCATOR (Fig. 13). In this period the overestimation between $14^{\circ} \mathrm{W}$ and $11^{\circ} \mathrm{W}$ is not present.

Both models have difficulties in forecasting the SST near the coast. For BIAS fields for the annual pe- 


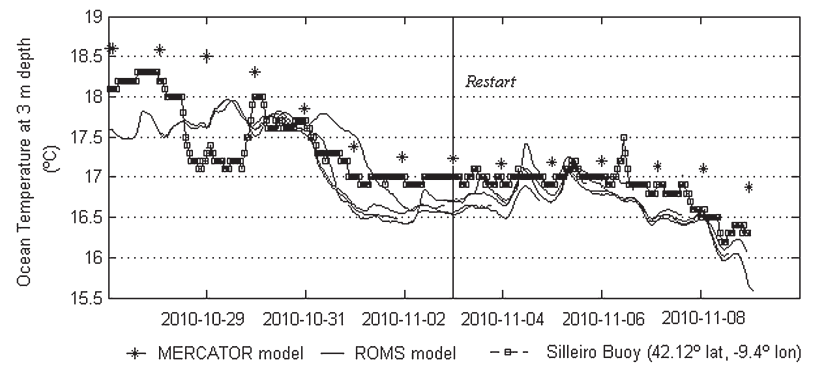

FIG. 14. - Time series of the ocean temperature at $3 \mathrm{~m}$ depth for winter 2010 for the Silleiro buoy, ROMS and MERCATOR.

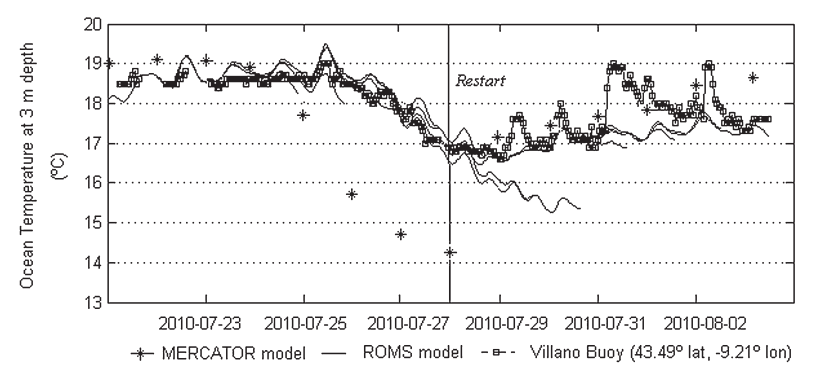

FIG. 15. - Time series of the ocean temperature at $3 \mathrm{~m}$ depth for summer 2010 for the Villano buoy, ROMS and MERCATOR.

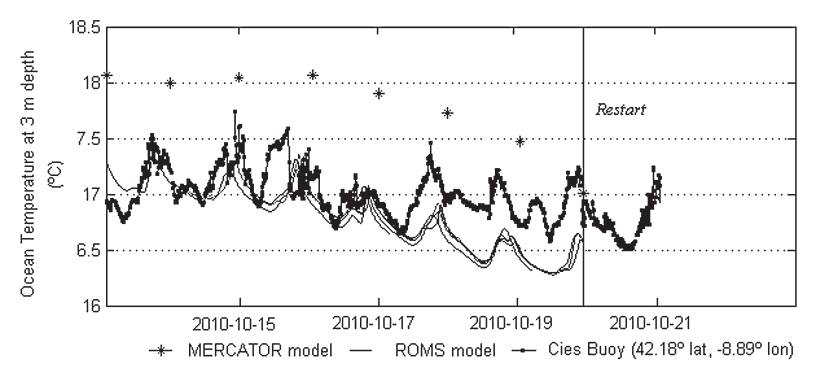

FIG. 16. - Time series of the ocean temperature at $3 \mathrm{~m}$ depth in winter 2010 for the Cies buoy, ROMS and MERCATOR.

riod and both of the monthly periods analysed, ROMS is able to produce lower values than its boundary condition model. The RMSE shows that ROMS has some clear problems in the area around $43^{\circ} \mathrm{N}$ near the coast, which shows a higher error. In addition, for the summer period there is no clear improvement in the RMSE, though there is in the BIAS. These two facts need to be investigated further as they show that some of coastal interactions may not be well represented in the model in summer. However, when the results are analyzed from a general perspective, especially on the annual statistics it is possible to see an improvement in the BIAS and RMSE from ROMS to MERCATOR on the coastal area of the northwestern Iberian Peninsula, between $42^{\circ} \mathrm{N}$ and $43^{\circ} \mathrm{N}$, where the fresh water inputs where included. Finally, ROMS clearly shows some problems between $14^{\circ} \mathrm{W}$ and $11^{\circ} \mathrm{W}$, though we do not have a reasonable explanation for this finding and it should be further investigated (Fig. 9).

Figures 14-16 show the time evolution for three periods of the ocean temperature at $3 \mathrm{~m}$ depth, compared with Silleiro, Villano-Sisargas and Cies buoy data, respectively, for three different periods. During all the periods analysed, results show that MERCATOR tends to underestimate temperature at $3 \mathrm{~m}$ depth, at the Villano-Sisargas buoy (Fig. 15), and to overestimate it at the Silleiro buoy (Fig. 14). However, ROMS shows good agreement between the SSTs modelled at these particular buoys.

For the Cies buoy, there is a resolution limitation in both ROMS and MERCATOR (Fig. 16), as this location is particularly close to the coast. Between 13 and 22 October the comparison between ROMS temperature and that observed at the Cies buoy shows a tendency of the model to begin to deviate from the measured data. Again, MERCATOR shows a higher limitation for forecasting the evolution of the temperature at this location.

Figures 14 to 16 present the consecutive runs of ROMS. Everyday a new forecast starts and covers a 4-day forecast period, and these periods are overlapped by subsequent forecast runs. Every 7 days a new restart cycle is performed and this could lead to jumps in the evolution of the ocean state in ROMS. However, even with this weekly restart ROMS is able to predict the evolution of the temperature in a continuous, closeto-the-observations time series, and without jumps between subsequent runs or when a restart cycle occurs. This is not always the case with MERCATOR, which shows a discontinuity before and after the new run (Fig. 15). Furthermore, at the end of the seven-day period of each MERCATOR forecast, just before every restart, it can be seen that MERCATOR drifts away from the observations. On the other hand, ROMS is able to stay closer to the observation at the end of each restart cycle (Figs 14 and 15). These results show that the chosen restart strategy improves the results for a boundary condition model that only runs once a week.

\section{CONCLUSIONS}

An ocean modelling system was developed for the northwestern Iberian Peninsula based on the ROMS model, and forced with regional scale models that include meteorological, hydrological and tidal data. Also, a high-resolution bathymetry for the coastal areas of the Galicia region was constructed using different sources of data including previous existing bathymetries and observation campaigns. The resulting data are made available through the RAIA Observatory so that other potential users can benefit from them.

A statistical analysis was performed for one year of simulations, comparing model data against OSTIA satellite data and buoys. When compared against OSTIA SST satellite data on an annual mean, ROMS showed good agreement with the observations. Two monthly periods, in summer and winter, were selected and a similar behaviour was observed; here the RMSE and BIAS remain lower than $1^{\circ} \mathrm{C}$. In both periods, ROMS was able to produce reasonable verification score values and even to outperform its boundary condi- 
tion model in some cases in the areas near the shore of the northwestern Iberian Peninsula. The comparison against buoys shows that ROMS is able to track threemetre depth temperature closer than MERCATOR and to maintain this skill further from the start of each restart cycle. This comparison also showed that some of the issues that appear with MERCATOR because it is run on a weekly basis are corrected in ROMS.

The aim of this paper is to describe the chosen operational setup and to show some preliminary results. At this point is not really possible to determine the factors that make ROMS perform well near the coast. Although it seems reasonable that taking into account local effects such as high-resolution winds and fluxes, river flows and bathymetry should improve the model prediction, a few additional tests must be performed to isolate the effect of the chosen configuration and the boundary condition models on the final result.

\section{ACKNOWLEDGEMENTS}

The authors wish to thank Pablo Carracedo for his contributions to this work, which were crucial to the design of the operational setup. We also acknowledge the use of the GNU Octave program for the analysis and graphics in this paper. GNU Octave is a freely redistributable high-level interpreted language software (information is available at http://www.gnu.org/software/ octave/). Finally we would like to thank Interreg IV-A project RAIA and INCITE project GIS-OCEANO that partly supported this research.

\section{REFERENCES}

Alvarez-Salgado X.A., Rosón G., Pérez F.F., Pazos Y. 1996. Nitrogen cycling in an estuarine upwelling system, the Ria de Arousa (NW Spain). Short-time-scale patterns of hydrodynamic and biogeochemical circulation. Mar. Ecol. Prog. Ser. 135: 259-273.

Alvarez-Salgado X.A., Figueiras F.G., Pérez F.F., Groom S., Nogueira E., Borges A.V., Chou L., Castro G.C., Moncoiffé G., Rios A.F., Miller A.E.J., Frankignoulle M., Savidge G., Wollast R. 2003. The Portugal coast counter current off NW Spain: new insights on its biogeochemical variability. Prog. Oceanogr. 56: 281-321.

Arnold J.G., Srinivasan P., Muttiah R.S, Williams J.R. 1998. Large area hydrologic modeling and assessment. Part I. Model development. J. Am. Water Resour. As. 34: 73-89.

Balseiro C.F., Carracedo P., Gómez B., Leitão P.C., Montero P., Naranjo L., Penabad E., Pérez-Muñuzuri V. 2003. Tracking the Prestige oil spill: an operational experience in simulation at MeteoGalicia. Weather 58: 452-458.

Blayo E., Debreu L. 2005. Revisiting open boundary conditions from the point of view of characteristic variables. Ocean Model. 9: 234-252.

Bode A., Varela M. 1998. Primary production and phytoplankton in three Galicia Rias Altas (NW Spain): seasonal and spatial variability. Sci. Mar. 62: 319-330.

Canuto V.M., Howard A., Cheng Y., Dubovikov M.S. 2001. Ocean turbulence Part I: One-point closure model-momentum and heat vertical diffusivities. J. Phys. Oceanogr. 31: 1413-1426.

Carracedo P., Balseiro C.F., Penabad E., Gómez B., Pérez-Muñuzuri V. 2005. One year validation of wave forecasting at Galician coast. J. Atmos. Ocean Sci. 10: 407-419.

Chapman D.C. 1985. Numerical treatment of cross-shelf open boundaries in a barotropic coastal ocean model. J. Phys. Oceanogr. 15: 1060-1075.

Ekman V.W. 1905. On the influence of the earth's rotation on ocean currents. Arkiv Matematik. Astron. Fysik 11: 52 pp.

Egbert G.D., Erofeeva S.V. 2002. Efficient inverse modeling of barotropic ocean tides. J. Atmos. Ocean Technol. 19: 183-204.

Fairall C.W., Bradley E.F, Rogers D.P., Edson J.B., Young G.S. 1996. Bulk parameterization of air-sea fluxes for tropical oceanglobal atmosphere Coupled Ocean Atmosphere Response Experiment. J. Geophys. Res. 101: 3747-3764.

Flather, R.A. 1976. A tidal model of the north-west European continental shelf. Mem. Soc. R. Sci. Liège 6: 141-164.

Haidvogel, D.B., Beckman A. 1999. Numerical Ocean Circulation Modeling. Imperial College Press, 318 pp.

Haynes R., Barton E.D., Pilling I. 1993. Development persistence and variability of upwelling filaments off the Atlantic Coast of the Iberian Peninsula. J. Geophys. Res. 98: 22681-22692.

Mason E., Colas F., Molemaker J., Shchepetkin A.F., Troupin C., McWilliams J.C., Sangrà P. 2011. Seasonal variability of the Canary Current: a numerical study. J. Geophys. Res. 116: C06001.

Mellor G.L., Yamada T. 1982. Development of a turbulence closure model for geophysical fluid problems. Rev. Geophys. 20: 851-875.

Oliveira P.B., Nolasco R., Dubert J., Moita T., Peliz A.J. 2009. Surface temperature, chlorophyll and advection patterns during a summer upwelling event off central Portugal. Cont. Shelf Res. 29: 759-774.

Peliz A., Rosa T., Santos A.M.P., Pissara J. 2002. Jets, eddies, and counterflows in the western Iberian upwelling system. J. Mar. Syst. 35: 61-77.

Shapiro R. 1970. Smoothing, filtering, and boundary effects. Rev. Geophys. Space Phys. 8: 359-387.

Shchepetkin A.F., McWilliams J.C. 2005. The Regional Ocean Modeling System: A split-explicit, free-surface, topography following coordinates ocean model. Ocean Model. 9: 347-404.

Song Y., Haidvogel D.B. 1994. A semi-implicit ocean circulation model using a generalized topography-following coordinate system. J. Comp. Phys. 115: 228-244.

Umlauf L., Burchard H. 2003. A generic length-scale equation for geophysical turbulence models. J. Mar. Res. 61: 235-265.

Received February 28, 2011. Accepted February 29, 2012.

Published online August 6, 2012. 